\title{
Molecular Basis for Cytolytic T-Lymphocyte Recognition of the Murine Cytomegalovirus Immediate-Early Protein pp89
}

\author{
MARGARITA DEL VAL, ${ }^{1}$ HANSJÜRGEN VOLKMER, ${ }^{1}$ JONATHAN B. ROTHBARD, ${ }^{2}$ STIPAN JONJIĆ,${ }^{1} \dagger$

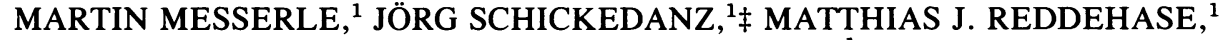 \\ AND ULRICH H. KOSZINOWSKI ${ }^{1} \S^{*}$ \\ Federal Research Centre for Virus Diseases of Animals, D-7400 Tübingen, Federal Republic of Germany, ${ }^{1}$ \\ and Imperial Cancer Research Fund, London, Great Britain ${ }^{2}$
}

Received 29 April 1988/Accepted 8 July 1988

\begin{abstract}
The murine cytomegalovirus protein pp89, which is encoded by gene ieI, is a nonstructural regulatory protein expressed in the immediate-early phase of the viral replication cycle and located mainly in the nucleus of infected cells. Protection of BALB/c $\left(H-2^{d}\right)$ mice against a lethal murine cytomegalovirus challenge infection is achieved by vaccination with a recombinant vaccinia virus, MCMV-ieI-VAC, expressing pp89 as the only murine cytomegalovirus gene product. The protection is entirely mediated by $\mathrm{T}$ lymphocytes of the $\mathrm{CD8}^{+}$ subset. In the present report, we analyzed the molecular basis of the recognition of pp89 by $\mathrm{BALB} / \mathrm{c} \mathrm{CD8}{ }^{+}$ cytolytic $\mathrm{T}$ lymphocytes. A series of internal and terminal deletion mutants of gene $i e I$ was constructed and cloned in vaccinia virus, and the antigenicity and immunogenicity of the fragments of pp89 expressed by the recombinants were studied. A region of only one-sixth of the protein, from amino acids 154 to 249 and encoded by the fourth exon of gene iel, was sufficient for both the recognition in vitro of the protein by pp89-specific cytotoxic $T$ lymphocytes and the induction in vivo of pp89-specific cytotoxic $T$ lymphocytes. By using synthetic peptides, the sequence between residues 161 and 179, which is located within the defined domain, was identified as an epitope presented to BALB/C cytotoxic $T$ lymphocytes by the class $I$ major histocompatibility antigen $L^{d}$.
\end{abstract}

Cytomegalovirus (CMV) is an ubiquitous human pathogen that is responsible for congenital malformations and causes serious disease in patients immunocompromised during organ transplantation or as a consequence of infection with human immunodeficiency virus. Adequate and efficient methods of prevention or treatment of CMV disease are lacking $(21,23,24)$. Recovery from CMV disease correlates with a cellular immune response rather than with the presence of CMV-neutralizing antibodies $(22,25)$.

The infection of the mouse with murine CMV (MCMV) serves as a model to study antiviral function and antigen specificity of different lymphocyte subsets $(10,15,17,27-30$, 41). By adoptive transfer experiments, it was shown that $T$ lymphocytes limit virus replication and prevent histopathology (30). In particular, a protective effect against lethal MCMV disease can be ascribed to $\mathrm{CD}^{+} \mathrm{T}$ lymphocytes specific for immunodominant antigens expressed in the immediate-early (IE) phase of the viral replication cycle $(28$, 29).

Within the 235-kilobase-pair MCMV DNA (7), gene expression during the IE phase is limited to a region of 12 kilobase pairs, which includes the transcription units ie1, ie2, and ie3 $(11,12)$. Gene ieI contained in transcription unit ie1 encodes the major MCMV IE protein, the nonstructural regulatory phosphoprotein pp89 (13). Virus-specific, major histocompatibility complex class I-restricted cytolytic T

* Corresponding author.

$\dagger$ Present address: Faculty of Medicine, University of Rijeka, YU-51000 Rijeka, Yugoslavia.

$\ddagger$ Present address: Institute for Molecular Biology and Biochemistry, Freie Universität, Arnimallee 22, 1000 West Berlin 33, Federal Republic of Germany.

$\S$ Present address: Department of Virology, Institute for Microbiology, University of Ulm, D-7900 Ulm, Federal Republic of Germany. lymphocytes (CTL) recognize pp89 $(15,17,41)$. Vaccination with a -recombinant vaccinia virus, MCMV-ieI-VAC, expressing pp89 as the only MCMV protein, induces protective immunity $(10,41)$.

The reason why IE antigens represent immunodominant antigens for $\mathrm{CD8}^{+} \mathrm{T}$ lymphocytes (28) is unknown. Transcription units ie 1 and ie 3 give rise to related transcripts and proteins, due to the differential usage of at least five exons. There is evidence for common usage of the transcription start site and the first three exons, the first of which serves as nontranslated leader $(12,13)$. Gene ieI, which encodes pp89, comprises the first four exons (13). Recognition by $\mathrm{CD}^{+} \mathrm{T}$ lymphocytes of amino acid sequences encoded by the second and third exon could offer an explanation for the immunodominance of IE antigens, because several IE proteins in addition to pp89 share these sequences.

Domains and epitopes of a protein antigen recognized by $\mathrm{CD}^{+} \mathrm{T}$ lymphocytes can be defined either by the expression of protein fragments in target cells $(37-39,43)$ or by incubation of target cells with synthetic peptides derived from the amino acid sequence of the protein $(38,40,43)$. In this communication, the combination of both methods allowed us to conclude that a single domain of pp89 is relevant for recognition by $\mathrm{CD}^{+} \mathrm{T}$ lymphocytes in BALB/c mice and led to the identification of an epitope 19 amino acids in length within this domain. The domain is entirely encoded by the fourth exon of gene ieI and contains the sequences essential for both immunogenicity and antigenicity of pp89.

\section{MATERIALS AND METHODS}

Mice. BALB/c mice $\left(\boldsymbol{H}-2^{d}\right.$ haplotype) were bred in our colony under specific-pathogen-free conditions.

Cells and viruses. The Smith strain of MCMV (VR-194; American Type Culture Collection, Rockville, Md.) was grown in third-passage BALB/c mouse embryo fibroblasts 
(MEF) and partially purified by sucrose gradient centrifugation. Wild-type and recombinant vaccinia viruses were grown in Vero cells (African green monkey kidney fibroblasts), and homogenized cell extracts were used for priming of mice and for the infection of the established cell lines KD2SV (simian virus 40-transformed kidney fibroblasts from B10.D2 $\left[H-2^{d}\right]$ mice) (26) and L (fibroblasts from $\mathrm{C} 3 \mathrm{H}$ $\left[\mathrm{H}-2^{\mathrm{k}}\right]$ mice). L cells transfected with the gene for the MHC class I molecule $\mathrm{L}^{\mathrm{d}}\left(\mathrm{L} / \mathrm{L}^{\mathrm{d}}\right.$ cells) were described previously (17). L cells transfected with $K^{d}$ and $D^{d}$ genes $\left(\mathrm{L} / \mathrm{K}^{\mathrm{d}}\right.$ cells, clone LSV 33-3 [5], and L/D ${ }^{d}$ cells, respectively) were provided by M. Cochet and J. P. Abastado (Institute Pasteur, Paris). Surface expression of the $L^{d}, D^{d}$, and $K^{d}$ molecules in the transfected cell lines was confirmed by cytofluorometric analysis with the monoclonal antibodies B22-249 (19), 34.5.8S, and 31.3.4S (5) specific for $\mathrm{L}^{\mathrm{d}}, \mathrm{D}^{\mathrm{d}}$, and $\mathrm{K}^{\mathrm{d}}$, respectively.

Construction of recombinant vaccinia viruses containing deletion mutants of gene $i$ I. The continuous open reading frame (ORF) of MCMV gene ieI, which was cloned as an EcoRI fragment in the vaccinia virus expression vector pGS62 (41), was transferred into plasmid pEMBL19(+) (6) for mutagenesis and studies of gene expression in eucaryotic cells. For this purpose, most of the ieI ORF, including the authentic ieI polyadenylation signal, was excised from pGS62 as an HincII-EcoRI fragment and introduced into the corresponding sites of pEMBL19 $(+)$. To provide the ieI ORF with the $5^{\prime}$ signals required for gene expression in eucaryotic cells, the DraI-HincII fragment from plasmid pIE111 encompassing the ieI promoter, the $5^{\prime}$ mRNA leader sequence, the first intron, the initiation codon, and coding sequences upstream of the HincII site (16) was cloned into the HincII site of the ieI ORF in pEMBL19(+). This plasmid was designated p62/3. In the double-stranded form, p62/3 was used for the construction of the deletion mutants, as described in Results. Single-stranded DNA isolated from supernatants of phage F1-infected Escherichia coli BMH7118 harboring $\mathrm{p} 62 / 3$ or the mutated plasmids was used for confirming the accuracy of the deletions by sequencing. Mutated iel genes were isolated from p62/3 as EcoRI fragments and, after cloning into plasmid pGS62, were inserted into vaccinia virus as described previously (41).

Immunoprecipitation. L cells infected $12 \mathrm{~h}$ before with recombinant vaccinia viruses at a multiplicity of infection of $20 \mathrm{PFU}$ per cell were labeled for $2 \mathrm{~h}$ with $170 \mu \mathrm{Ci}$ of $\left[{ }^{35} \mathrm{~S}\right]$ methionine per $\mathrm{ml}$ in methionine-free medium, and immunoprecipitation of the cell lysates was performed as described previously (14) with serum from mice latently infected with MCMV and antiserum raised in rabbits against the synthetic peptide $\mathrm{P}(34-53)$ of pp89 coupled to bovine serum albumin $(1,4)$. The immunoprecipitated polypeptides were analyzed by 10 to $20 \%$ acrylamide gradient gel electrophoresis.

Synthetic peptides. The peptides were synthesized by using the Merrifield solid-phase techniques on an Applied Biosystems peptide synthesizer and purified by high-pressure liquid chromatography to more than $90 \%$ purity (32). They were designated $\mathrm{P}(x-y)$, where $x$ and $y$ indicate the $\mathrm{N}$ and C-terminal amino acids, respectively, within the sequence of pp89.

Generation of cytolytic effector cells. The $L^{d}$-restricted pp89-specific CTL clone IE1 has been described previously $(17,26,31)$. For the production of polyclonal pp89-specific CTL, mice were infected intravenously with $5 \times 10^{5} \mathrm{PFU}$ of recombinant vaccinia viruses. Three weeks later, spleen cells were cultured at a concentration of $1.5 \times 10^{6}$ cells per $\mathrm{ml}$ together with $1 \times 10^{5} \mathrm{PFU}$ of MCMV and $1.5 \times 10^{5}$ stimulator cells per ml. Irradiated $(30 \mathrm{~Gy})$ spleen cells from 8-week-old mice which had been irradiated $(6 \mathrm{~Gy})$ and lethally infected $\left(2 \times 10^{5}\right.$ PFU of MCMV, intraperitoneally) 8 to 12 days before served as stimulator cells. At day 5 of culture, $25 \mathrm{U}$ of recombinant human interleukin 2 (Sandoz Forschungsinstitut, Vienna, Austria) was added per ml, and the cultures were tested for cytolytic activity at day 7. For the preparation of polyclonal MCMV-specific CTL, the same procedure was followed, except that mice latently infected with MCMV were used as the source of effector cells. For the generation of polyclonal vaccinia virus-specific CTL, mice were infected in one hind footpad with $2 \times 10^{7}$ PFU of wild-type vaccinia virus. At 6 days later, the popliteal lymph node cells were taken and propagated in vitro for 4 days in the presence of $100 \mathrm{U}$ of recombinant human interleukin 2 per $\mathrm{ml}$.

Target cells and cytolytic assays. For selective expression of IE genes, MEF were infected with MCMV at a multiplicity of infection of $20 \mathrm{PFU}$ per cell by centrifugation $(800 \times g$, $30 \mathrm{~min}$ ) in the presence of $50 \mu \mathrm{g}$ of cycloheximide per $\mathrm{ml}$, which was replaced $3 \mathrm{~h}$ later by $5 \mu \mathrm{g}$ of actinomycin D (28) per ml. KD2SV cells and L cells were infected for $15 \mathrm{~h}$ with wild-type or recombinant vaccinia viruses at a multiplicity of 20 PFU per cell. The target cells were then trypsinized and labeled with $\mathrm{Na}_{2}{ }^{51} \mathrm{CrO}_{4}$ for $90 \mathrm{~min}$, and a standard 3-h cytolytic assay was performed (28) with 1,000 target cells and graded numbers of effector cells in twofold dilution steps. Data represent the mean percentage of specific lysis from three replicate cultures. For testing synthetic peptides, the cells were pulsed with $100 \mu \mathrm{M}$ peptide during the 90 -min ${ }^{51} \mathrm{Cr}$ labeling period, and excess peptide was removed by washing of cells before incubation with effector cells (40). Peptides that were scored negative by this method were additionally tested after a second procedure, in which the already ${ }^{51} \mathrm{Cr}$-labeled cells were dispensed into 96-well microdilution plates containing the peptides at concentrations up to $100 \mu \mathrm{M}$. After incubation for $30 \mathrm{~min}$ at $37^{\circ} \mathrm{C}$, the cytolytic effector cells were added, and the peptides were kept throughout the assay (40).

\section{RESULTS}

Construction of the recombinant vaccinia viruses encoding deletion mutants of pp89 gene ieI. The major IE protein of MCMV, pp89, is translated from the major IE mRNA, 2.75 kilobases in length, derived from transcription unit iel of the MCMV genome (11-14). We have previously reported the cloning into vaccinia virus of the continuous ieI ORF corresponding to this major mRNA (41) (Fig. 1A). The pp89 expressed by the recombinant MCMV-ieI-VAC not only is recognized in vitro by MCMV-specific CTL but can also induce pp89-specific CTL in vivo that mediate protective immunity against lethal MCMV challenge $(10,41)$. The vaccinia virus vector system was now employed for mapping the domains of pp89 that are essential for the antigenicity and the immunogenicity of the protein for major histocompatibility complex class I-restricted CTL. Our strategy was to study the effect that removal of defined regions of pp89 has on the cellular immune response.

A series of deletions spanning altogether $97 \%$ of the pp89 sequence were produced within gene ieI cloned in plasmid $\mathrm{p} 62 / 3$, and the mutated genes were recombined into vaccinia virus (Fig. 1B). The selected restriction enzymes served to generate in-frame deletions. The DNA sequences flanking the deletion sites were checked. Deletion mutant MCMV- 
(A)

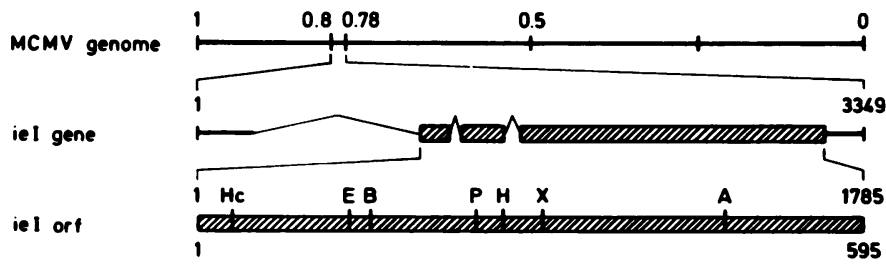

(B)

Recombinant vaccinia virus

MCMV -iel - VAC

MCMV-ie I (DA)-VAC

MCMV-ie I ( $\triangle F)$-VAC

MCMV-iel $(\triangle C)$-VAC

MCMV-ie I $(\Delta H)$-VAC

MCMV-iel $(\Delta J)$-VAC

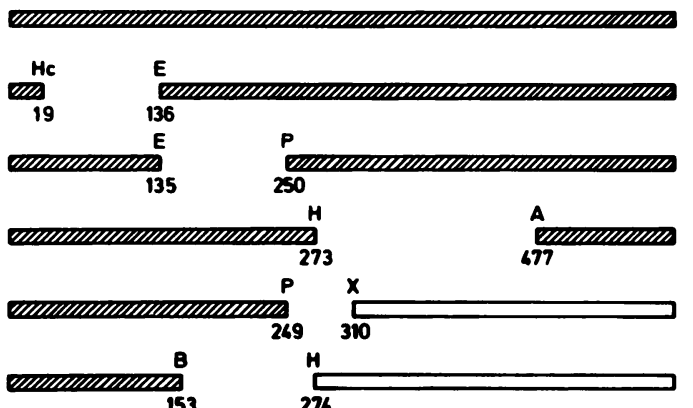

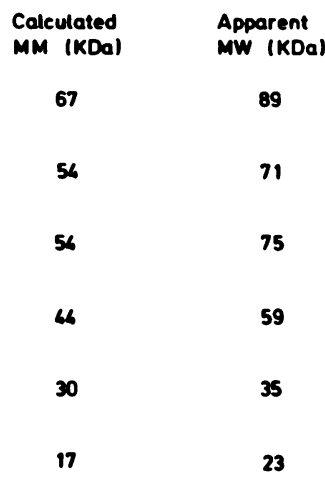

FIG. 1. Structure of the deletion mutants of gene iel encoding pp89. (A) The MCMV ieI gene, which is located between 0.78 and 0.80 map units of the MCMV genome, has a length of 3,349 base pairs and comprises four exons, the first of which is noncoding (13). The continuous ieI ORF, 1,785 base pairs in length (13), was derived from the iel gene by site-directed mutagenesis (41). (B) Deletion mutants of the iel ORF, drawn to the same scale as the iel ORF, were constructed and then cloned into vaccinia virus. Relevant restriction enzyme cleavage sites are indicated as follows: Hc, HincII; E, EcoRV; B, BglII; P, PvuII; H, HindIII; X, XbaI; A, Asp 718. The numbers below the constructs refer to amino acid positions in pp89. For the mutated proteins, the residues of the authentic pp89 sequence flanking the deletions are indicated. Hatched bars represent the pp89 sequence expressed, whereas open bars in $\Delta H$ and $\Delta \mathrm{J}$ indicate DNA sequences present in the recombinants but not expressed due to a frame shift that created new stop codons. For each recombinant virus, the molecular mass (MM) of the encoded protein was calculated from the amino acid sequence and is shown in comparison with the apparent molecular mass (MW) of the expression products that were detected after immunoprecipitation and sodium dodecyl sulfate-polyacrylamide gel electrophoresis.

ieI-( $\triangle \mathrm{A})-\mathrm{VAC}$ (abbreviated as $\Delta \mathrm{A})$ was constructed by EcoRV digestion of p62/3. The ieI ORF contains one EcoRV site, and a second EcoRV site is located in the intron that separates the nontranslated leader sequence of the first exon from the protein-coding sequences of the ORF (13). Cleavage resulted in the deletion of the single EcoRV fragment. This isolated EcoRV fragment was digested with HincII, and the shorter EcoRV-HincII fragment containing the translation start site was reintroduced into the p62/3 that lacked the EcoRV fragment. $\Delta \mathrm{F}$ was constructed as follows: plasmid p62/3 contains three $P v u I I$ sites, only one of which is located in the ieI ORF. A partial PvuII digestion linearized the vector. Subsequent cleavage with EcoRV removed the $E c o$ RV fragment and the EcoRV-PvuII fragment upstream of the $P v u \mathrm{II}$ site in the coding region. The isolated $E c o \mathrm{RV}$ fragment was then reintroduced at its original position. Although the deletions in $\Delta \mathrm{A}$ and $\Delta \mathrm{F}$ were sealed by blunt end ligation of fragments, the preparation of the deletion mutants $\Delta \mathrm{C}, \Delta \mathrm{H}$, and $\Delta \mathrm{J}$ required the creation of blunt ends by using the Klenow fragment of DNA polymerase I before ligation. To generate mutant $\Delta \mathrm{C}$, cleavage with HindIII and Asp-718 removed all MCMV sequences between the HindIII site in the multiple cloning site of plasmid pEMBL19(+) and the Asp-718 site in the ieI ORF. The isolated HindIII fragment was reintegrated, resulting in the loss of sequences between the HindIII and Asp-718 sites in the ieI ORF. Deletion mutants $\Delta \mathrm{J}$ and $\Delta \mathrm{H}$ were also originally intended to express the carboxy terminus of the protein (Fig. 1B). During the deletion procedure, however, 1 and 2 base pairs, respectively, were lost, thereby causing frameshifts that resulted in the addition of 1 and 16 amino acids, respectively, preceding translation termination codons. $\Delta H$ was constructed by removal of the HincII-XbaI fragment and subsequent reintroduction of the smaller HincII-PvuII subfragment, and $\Delta \mathrm{J}$ was constructed by removal of the HincII-HindIII fragment followed by reintroduction of the HincII-BglII subfragment.

The expression of the pp89 deletion mutants in cells infected with the recombinant vaccinia viruses was confirmed by immunoprecipitation (Fig. 2). In all cases, the apparent molecular weight of the pp89 fragments was higher than the calculated molecular mass (Fig. 1 and 2). This was not unexpected, because the authentic pp89 is known to migrate by a factor of 1.3 slower than expected from size calculation (13). If the shift to higher molecular weight of pp89 is due to contributions from certain regions of the protein, we should expect to find different degrees of shift in the different deletion mutants of pp89. Indeed, when the calculated molecular masses were compared with the apparent molecular weights, the factor of 1.3 did not apply to all pp89 variants. In particular, the 35-kilodalton (kDa) fragment of pp89 expressed by the recombinant $\Delta H$ (Fig. 2) had migration properties in between the calculated molecular mass $(30 \mathrm{kDa})$ and the expected apparent molecular mass (40 $\mathrm{kDa}$. This suggests that the C-terminal region of pp89 missing in $\Delta \mathrm{H}$ is perhaps rich in posttranslational modifications. A minor difference in migration properties was also observed in pp89 fragment expressed by the recombinant $\Delta \mathrm{F}$ (Fig. 1 and 2).

Mapping of the regions of pp89 essential for the antigenicity 


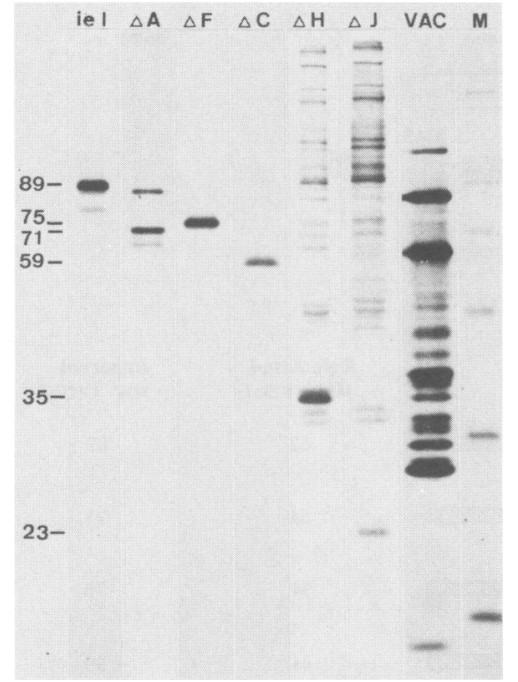

FIG. 2. Expression of deletion mutants of pp89 in cells infected with recombinant vaccinia viruses. $L$ cells were labeled for $2 \mathrm{~h}$ with $\left[{ }^{35} \mathrm{~S}\right]$ methionine $12 \mathrm{~h}$ after infection with the indicated recombinants, and cell lysates, except that of recombinant $\Delta \mathrm{A}$, were immunoprecipitated with rabbit antiserum to peptide $\mathrm{P}(34-53)$. For the immunoprecipitation of the $\Delta \mathrm{A}$ product, which lacks residues 34 through 53, MCMV immune serum was used. Sodium dodecyl sulfatepolyacrylamide gel electrophoresis of the immunoprecipitates and of a representative lysate containing the proteins specified by the vaccinia virus vector (VAC) is shown. Apparent molecular masses of the pp89 fragments are indicated in kilodaltons. Molecular weight standards (M): 200, 92.5, 69, 46, 30, and $14.3 \mathrm{kDa}$.

of the protein for BALB/c CTL. The recognition by BALB/c MCMV-specific CTL of the fragments of pp89 expressed by the recombinant vaccinia viruses was analyzed by using KD2SV cells, which express all $\mathrm{H}-2^{\mathrm{d}}$ class I molecules. Cells infected with the recombinants $\Delta \mathrm{A}, \Delta \mathrm{C}$, and $\Delta \mathrm{H}$ were recognized by MCMV-specific polyclonal CTL to the same extent as were those infected by MCMV-ieI-VAC encoding the whole protein (Fig. 3). On the other hand, cells infected with recombinants $\Delta \mathrm{F}$ and $\Delta \mathrm{J}$ and control cells infected with wild-type vaccinia virus were not lysed. The fact that $\Delta \mathrm{F}$ was not recognized, whereas $\Delta \mathrm{A}$ and $\Delta \mathrm{H}$, which lack regions of pp89 flanking the one that is missing in $\Delta F$ (Fig. 1), were recognized, indicated that only the domain from amino acids 136 to 249 was essential for the antigenicity of pp89. More- over, taking into account that $\Delta \mathrm{J}$ was also not recognized, this domain could be further narrowed to pp89 amino acids 154 to 249.

The antigenic domain of pp89 is required for the immunogenicity of the protein in BALB/c mice. We studied next the immunogenic properties of the fragments of $\mathrm{pp} 89$ expressed by the recombinant viruses. It has been previously shown that pp89 expressed by the recombinant MCMV-ieI-VAC is able to prime pp89-specific CTL in BALB/c mice (41). We now found that the pp89 fragments expressed by the recombinants $\Delta \mathrm{A}, \Delta \mathrm{C}$, and $\Delta \mathrm{H}$ were as effective as the whole protein in eliciting in vivo CTL that recognized pp89 expressed in MCMV-infected cells (Fig. 4). On the other hand, the removal of the antigenic domain of the protein in $\Delta \mathrm{F}$ and $\Delta \mathrm{J}$ rendered these recombinants as ineffective in priming for a pp89-specific CTL response as was wild-type vaccinia virus.

These results demonstrated that the only domain of pp89 essential for priming and recognition by BALB/c CTL, in the context of any $\mathrm{H}-2^{\mathrm{d}}$ class I molecule, was the one located between amino acids 154 and 249. Removal of this antigenic domain from the protein revealed that no immunogenic domains exist outside of it.

Identification of amino acid sequences recognized by CTL within the domain defined with the deletion mutants. The data presented so far provided only negative evidence as to the location within the protein of the epitopes recognized by CTL. For positive evidence, in parallel to the analysis of the deletion mutants, we screened the pp89 sequence for motifs that could represent epitopes for T lymphocytes (33). The peptides $\mathrm{P}(34-53), \mathrm{P}(87-104), \mathrm{P}(92-106), \mathrm{P}(271-295), \mathrm{P}(315-$ $328)$, and $P(451-466)$ were synthesized and tested for their ability to render uninfected cells that express $\boldsymbol{H}-2^{d}$ class I surface glycoproteins susceptible to lysis by pp89-specific CTL. None of these peptides, all of which fortuitously lay outside the domain between amino acids 154 and 249, was recognized by the CTL (data not shown), thus supporting the results obtained with the deletion mutants.

After completion of the deletion analysis, we focused the search for putative epitope sequences on the defined domain, and the peptides $\mathrm{P}(161-179)$ and $\mathrm{P}(197-204)$ were synthesized and tested. When pulsed with $\mathrm{P}(161-179)$, KD2SV cells, which express all $H-2^{d}$ class I molecules, were recognized and lysed by both a polyclonal MCMV-specific CTL population and the pp89-specific, $L^{d}$-restricted CTL clone IE1 (Fig. 5). KD2SV cells pulsed with $\mathrm{P}(194-207)$ as

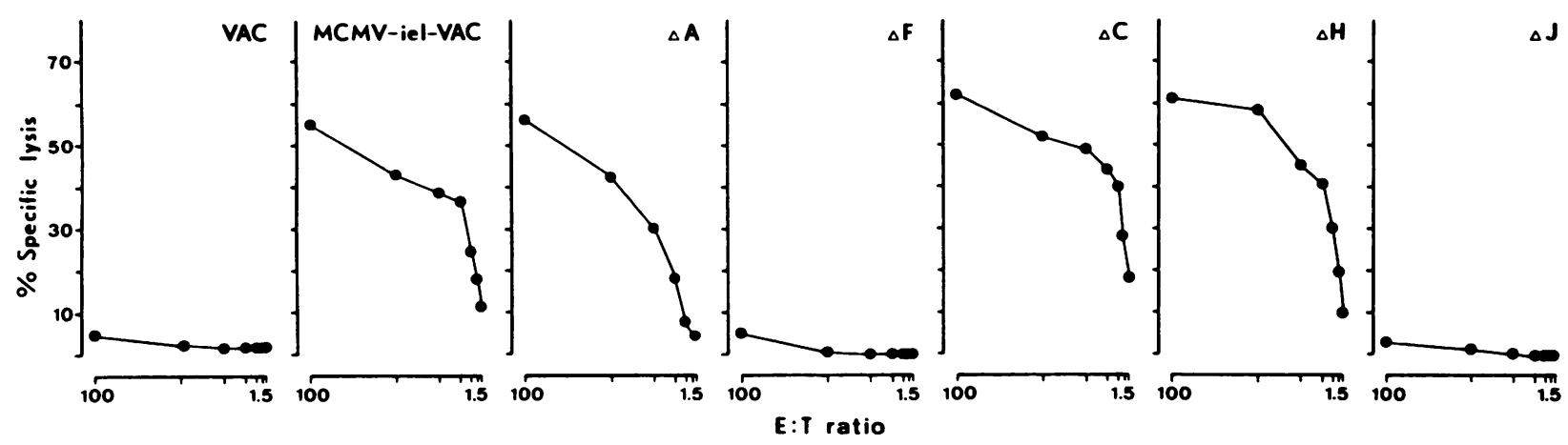

FIG. 3. Recognition by BALB/c MCMV-specific CTL of deletion mutants of pp89 expressed in recombinant vaccinia virus-infected cells. MCMV-specific CTL were generated by in vitro restimulation with MCMV of spleen cells derived from mice that were latently infected with MCMV. KD2SV cells infected either with wild-type vaccinia virus (VAC) or with the indicated recombinants were used as target cells in the cytolytic assay. The $\mathrm{E}: \mathrm{T}$ ratio is the ratio of effector cells to target cells. 

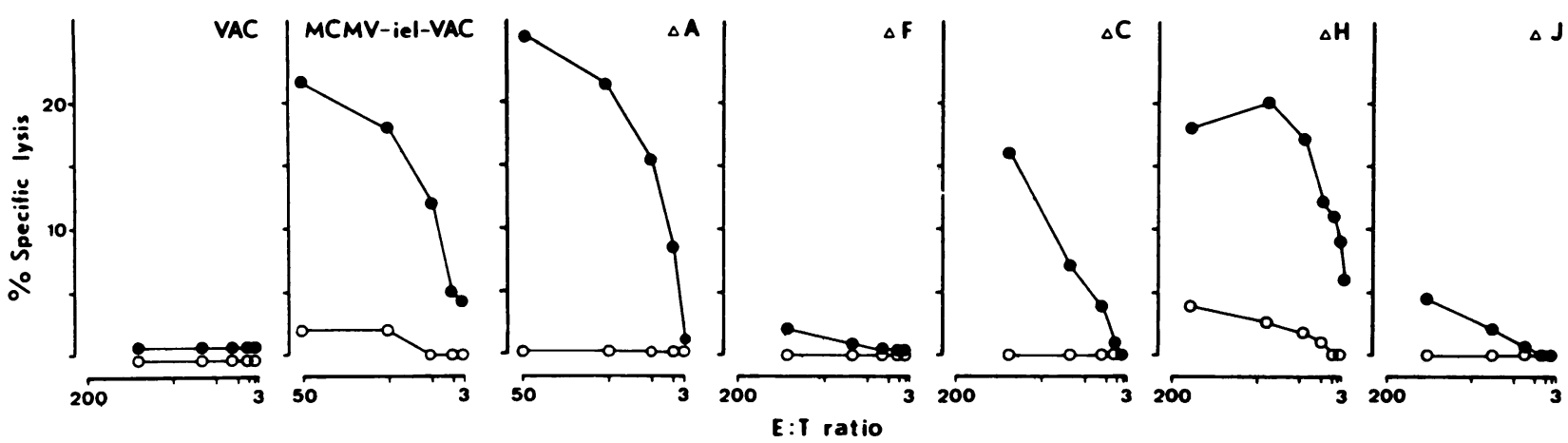

FIG. 4. Priming of pp89-specific CTL by deletion mutants of pp89 expressed by recombinant vaccinia viruses. Spleen cells were obtained from BALB/c mice 3 weeks after intravenous infection with $5 \times 10^{7}$ PFU of either wild-type vaccinia virus (VAC) or the indicated recombinants. After a secondary restimulation in vitro with MCMV, the specific cytolytic activity of the generated CTL was assayed on MEF infected with MCMV under conditions of selective and enhanced expression of IE genes $(\bullet)$ or, as a control, on uninfected MEF (O).

well as $\mathrm{KD} 2 \mathrm{SV}$ cells incubated without peptides were not lysed. L cells $\left(H-2^{k}\right)$, which lack $H-2^{d}$ molecules, were not able to present any of the peptides. We therefore concluded that the region from amino acids 161 to 179 in pp89 constitutes an epitope recognized by $H-2^{d}$ class I-restricted CTL.

Since recognition of pp89 by the CTL clone IE1 is restricted to the $\mathrm{L}^{\mathrm{d}}$ glycoprotein $(17,26)$, we expected $P(161-179)$ to be presented in association with the $L^{d}$ molecule. We could not exclude, however, the possibility that it might also be presented by other $\boldsymbol{H}-2^{d}$ class I glycoproteins, since for several epitopes recognized in association with MHC class II glycoproteins presentation by more than one restriction element has been described $(18,35)$. The conversion to targets with the peptide $\mathrm{P}(161-179)$ of $\mathrm{L}$ cells transfected with the gene encoding the MHC class I molecule $\mathrm{L}^{\mathrm{d}}$, but not of those transfected with $\mathrm{D}^{\mathbf{d}}$ or $\mathrm{K}^{\mathrm{d}}$, confirmed the selective $L^{d}$-restricted recognition of this epitope by both

$P(161-179)$

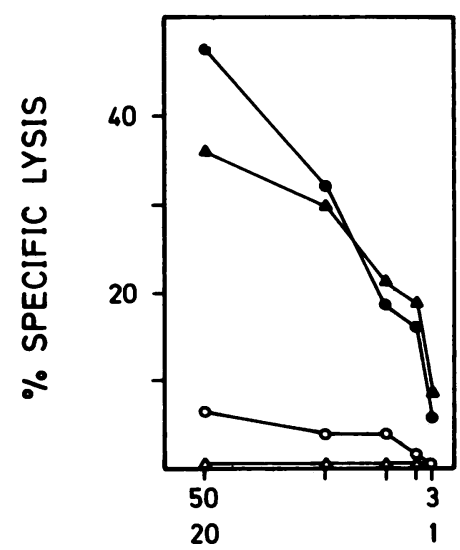

$P(194-207)$

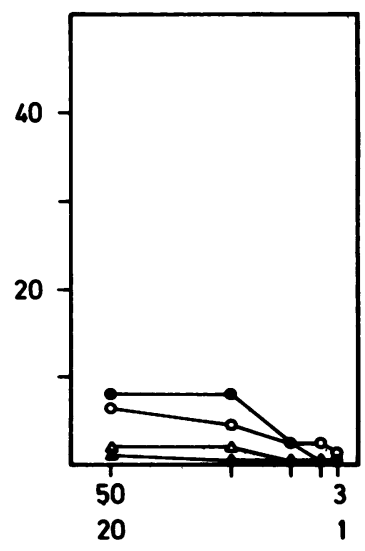

E:T RATIO

FIG. 5. Recognition by BALB/c MCMV-specific CTL of a synthetic peptide derived from the amino acid sequence of pp89. Synthetic peptides $\mathrm{P}(161-179)$ and $\mathrm{P}(194-207)$, corresponding to pp89 residues 161 to 179 and 194 to 207 , respectively, were used at a concentration of $100 \mu \mathrm{M}$ to pulse uninfected KD2SV cells $\left(H-2^{d}\right)$ $(\Theta, \Delta)$ or $\mathrm{L}$ cells $\left(H-2^{k}\right)(O, \Delta)$ during the labeling with ${ }^{51} \mathrm{Cr}$. As effectors in the cytolytic assay, either MCMV-specific polyclonal CTL (O, O; E:T ratios ranging from 50:1 to 3:1) or the CTL clone IE1 $(\Delta, \Delta ; E: T$ ratios ranging from $20: 1$ to $1: 1)$ were used. polyclonal and clonal CTL (Fig. 6A). Surface expression of the $L^{d}, D^{d}$, and $K^{d}$ molecules was confirmed for each of the transfected cell lines by cytofluorometric analysis with the respective monoclonal antibodies specific for $\mathrm{L}^{\mathbf{d}}, \mathrm{D}^{\mathbf{d}}$, and $\mathrm{K}^{\mathrm{d}}$ (data not shown). In addition, all three MHC class I gene transfectants, but not the untransfected L cells (data not shown), were able to present vaccinia virus antigens to BALB/c vaccinia-specific $H-2^{d}$-restricted polyclonal CTL (Fig. 6B), thus providing evidence for the functional integrity of the transfected gene products.

In conclusion, the region from amino acids 154 to 249 of pp89 represents the antigenic and immunogenic domain of the protein for BALB/c MHC class I-restricted CTL and contains an epitope that is recognized after presentation by the $\mathrm{L}^{\mathrm{d}}$ molecule (Fig. 7).

\section{DISCUSSION}

Vaccination of mice with a recombinant vaccinia virus, MCMV-ieI-VAC, encoding the IE protein pp89 as the only MCMV gene product (41), can protect against a lethal challenge infection with MCMV. Protection is mediated by pp89-specific $\mathrm{CD}^{+} \mathrm{T}$ lymphocytes (10). These results led us to study which regions of the IE protein pp89 are immunogenic and antigenic for the virus-specific and MHC class I-restricted CTL response in BALB/c $\left(H-2^{d}\right)$ mice. The results show that the pp89-specific CTL response is entirely directed to a domain comprising only one-sixth of the whole protein, located between pp89 residues 154 and 249 . An epitope 19 amino acids in length was identified within this region. When presented by the $M H C$ class I glycoprotein $L^{d}$, this epitope was recognized by both polyclonal MCMVspecific CTL and the pp89-specific CTL clone IE1.

According to current concepts of antigen processing and presentation for $\mathrm{T}$ lymphocytes, most protein antigens undergo intracellular fragmentation yielding short peptides (36, 40). After binding to a single site on surface MHC molecules $(2,9)$, such peptides are recognized by the antigen-specific T-cell receptor (34). Recognition of protein antigens by specific CTL has been demonstrated when target cells either synthesized whole or fragmented proteins after transfection $(15,17,37-39,43)$ or were incubated with synthetic peptides derived from the amino acid sequence of the protein $(38,40$, 43). By using these strategies, antigenic sequences of some proteins could be defined. Although we have successfully employed the transfection of cells to study the recognition of pp89 by CTL $(15,17)$, the use of transfected cell lines is 
(A) $P(16) \cdot 179)$
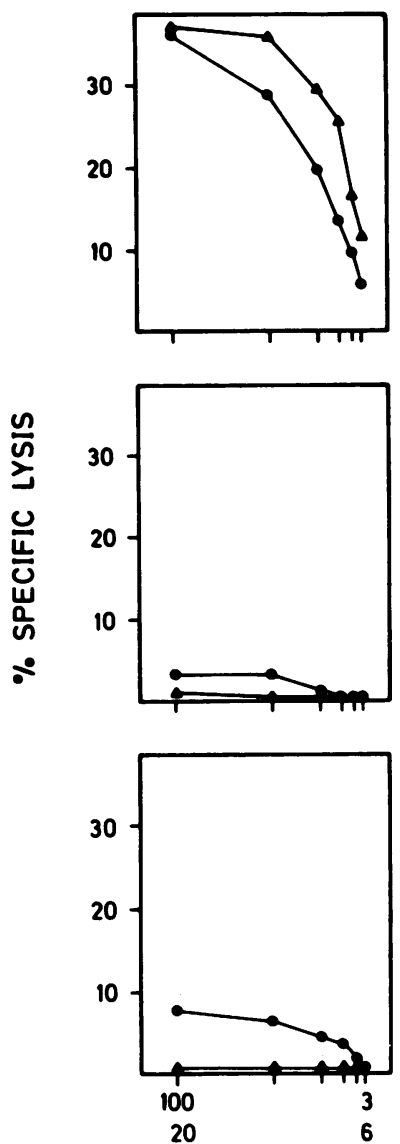

$P(196-207)$
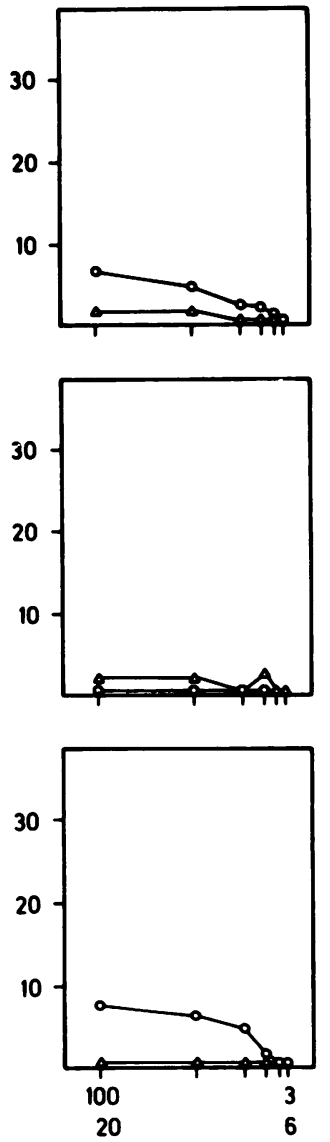

$L / L^{d}$

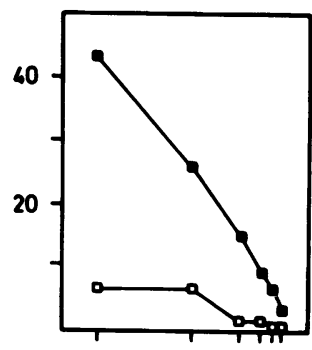

$L / 0^{d}$

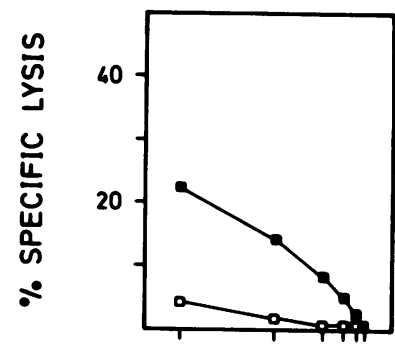

$L / K^{d}$
(B)

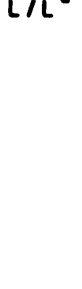

$1 / 0^{d}$

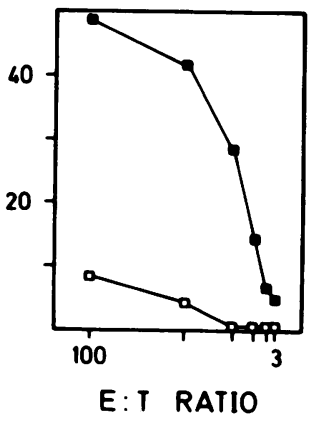

$L / K^{d}$

E:T RATIO

FIG. 6. Presentation of the pp89-derived synthetic peptide $\mathrm{P}(161-179)$ by the $M H C$ class I glycoprotein $L^{d}$. A. The $L / L^{d}$, $L / D^{d}$, and $L / K^{d}$ cells were pulsed with $\mathrm{P}(161-179)$ or $\mathrm{P}(194-207)$ peptides, and their recognition by either MCMV-specific polyclonal CTL (O, O; E:T ratios ranging from 100:1 to 3:1) or by the CTL clone IE1 $(\Delta, \triangle$; E:T ratios ranging from 20:1 to $0.6: 1)$ was tested. B. Recognition by vaccinia virus-specific polyclonal CTL of $L / L^{d}, L / D^{d}$, and $L / K^{d}$ cells that were either not infected ( $\square$ ) or infected with wild-type vaccinia virus ( $\square$ ).

limited. On the other hand, expression of gene fragments in vaccinia virus offers the advantage that each construct can be tested in vitro and in vivo in a variety of MHC haplotypes.

The approach to construct a series of C-terminal truncations of a protein and to express them in vaccinia virus

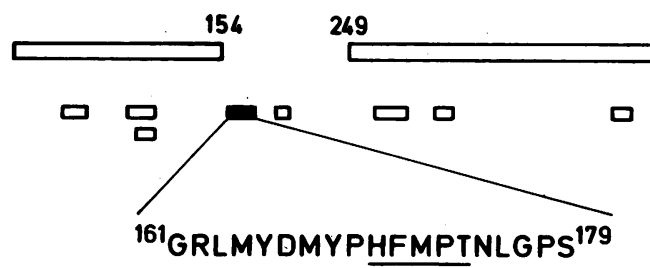

FIG. 7. Epitope for BALB/c CTL in MCMV IE protein pp89. The open bars represent the regions of pp89 (595 amino acids) that are not essential for the CTL response. Small boxes indicate the positions of sequences tested with synthetic peptides. The amino acid sequence of the epitope defined by synthetic peptide $\mathrm{P}(161-179)$ (filled box) is given in the one-letter code, with the proposed motif for T-lymphocyte recognition underlined. recombinants has recently been successfully used to map an epitope detected by CTL clones specific for the glycoprotein of the lymphocytic choriomeningitis virus (43). We followed a similar but slightly different strategy. We intended not only to define regions of pp89 which are relevant but also to dismiss the regions that do not contribute to the antigenicity and immunogenicity of the protein. This could not be achieved with C-terminal deletions, because this approach can only define but does not exclude domains, unless the protein is truncated to an $\mathrm{N}$-terminal fragment which fails to be recognized by CTL. We therefore turned to the construction of internal in-frame deletion mutants of pp89.

It was expected that, if several domains within pp89 with antigenic and immunogenic properties did exist, all in-frame deletion mutants should be detected by some CTL in a polyclonal population. Unlike the simian virus $40 \mathrm{~T}$ antigen, in which antigenic epitopes located in several regions of the protein are recognized by CTL (37), only one domain of pp89 was found to be important for CTL induction and antigen recognition by $\mathrm{CTL}$ in $\mathrm{BALB} / \mathrm{c}$ mice. This domain was negatively defined by deletion mutant $\Delta \mathrm{F}$ lacking amino acids 136 through 249 . Recognition by CTL of mutants $\Delta \mathrm{A}$ and $\Delta \mathrm{H}$ lacking the residues 20 through 135 and 250 through 595 , respectively, confirmed that all epitopes must be lo- 
cated within this domain. A role for the first 153 amino acids was excluded with mutant $\Delta \mathbf{J}$, and thus the relevant domain could be confined to the residues 154 through 249 . The possibility is not excluded that epitopes located at or very close to the deletion points in $\Delta \mathrm{F}$ or $\Delta \mathrm{J}$ might exist and have been disrupted by the deletions. For other proteins, regions far away from the actual epitope may influence the intensity of the T-cell response to the epitope (8). It has been suggested that these distant regions might be involved in the processing of the protein. If this is the case also in pp89, such regions should also be contained within the defined domain, since deletion of all other regions affected neither the antigenicity nor the immunogenicity of the protein.

The domain is encoded entirely by the fourth exon of gene ieI in transcription unit ie1. mRNA selected by DNA sequences from the transcription unit ie 3 and translated into protein does not hybridize to the fourth exon $(12,13)$. Thus, ie3 products cannot contribute to the pp89-specific CTL response. Previous work has identified proteins of 67,51 , and $31 \mathrm{kDa}$ in size that contain sequences derived from the first three exons of transcription unit ie1 $(12,13)$. In addition, all of them share with pp89 the monoclonal antibody 6/20/1 binding site (12), which has recently been mapped to amino acid sequences encoded by the $3^{\prime}$ region of the fourth exon (M. Messerle et al., manuscript in preparation). Considering the reduced size of these ie1 products, it is likely that some, if not all, of these smaller ie1 products do not contain the CTL epitope of pp89, which is encoded by the 5' region of the fourth exon. Our results thus disfavor the idea that several related IE proteins carrying the same epitope account for the immunodominance of IE antigens.

For positive identification of epitopes within the antigenic and immunogenic domain of pp89, we made use of an algorithm proposed to predict epitopes recognized by $T$ lymphocytes (33). A statistical analysis of several epitopes has revealed a common sequence pattern consisting of a charged amino acid or glycine followed by two or three hydrophobic amino acids and a charged or polar amino acid. We screened the whole pp89 for such motifs, and six selected sequences were synthesized. They all failed to render uninfected $\boldsymbol{H}-2^{d}$ target cells susceptible to lysis by both MCMV-specific polyclonal CTL and the pp89-specific CTL clone IE1. It was not until we had defined the antigenic domain and selected two peptides within it that an epitope recognized by specific polyclonal and clonal CTL was found. The epitope comprises amino acids 161 to 179 , contains a proposed pattern at residues 170 to 174 , and is the first described to be presented by the major histocompatibility complex class I molecule $\mathrm{L}^{\mathrm{d}}$. Since some degree of similarity is observed for epitopes presented by the same restriction molecule (33), we hope that the identification of this epitope will help in the search for $L^{d}$-restricted epitopes in other protein antigens.

An unusual feature of this peptide is the fact that it contains three prolines, an amino acid seldom found in $\alpha$-helices and in epitopes recognized by $T$ lymphocytes, many of which are supposed to adopt an $\alpha$-helical conformation $(20,33)$. By studying the recognition by the CTL clone IE1 of shorter or substituted derivatives of this peptide, we expect to find out the optimal length of the epitope and which residues are important for binding to the class I molecule and for interaction with the T-cell receptor.

The recognition of the epitope at residues 161 through 179 presented by the $\mathrm{L}^{\mathrm{d}}$ molecule does not exclude the possibility that CTL from the BALB/c strain can recognize also other epitopes in pp89. We predict, however, that, if addi- tional epitopes do exist they should be located within or directly adjacent to residues 154 through 249 . Final proof for or against the existence of other pp89 epitopes presented by class I molecules of the $\boldsymbol{H}-2^{d}$ haplotype can be achieved after definition of critical residues in the epitope core sequence of residues 161 through 179 , introduction of point mutations in gene iel by site-directed mutagenesis, and study of the immunological properties of the mutated pp89.

A long-term aim of our studies on the immunobiology of the murine CMV infection is to test the feasibility of active and passive immunization against CMV disease. We have previously shown that vaccination with a vaccinia virus recombinant expressing pp89 (10) and cytotherapy with IE-specific $\mathrm{CD}^{+} \mathrm{T}$ lymphocytes (29) are protective. The observation that the major IE protein of human CMV is also a major antigen for human CTL $(3 ; \mathrm{L}$. K. Borysiewicz and J. G. B. Sissons, personal communication) encourages extrapolation of the results to the human CMV disease. Since vaccination with live vaccinia virus recombinants is not advisable in the immunosuppressed host, subunit vaccines have to be developed. Recently it was shown that immunization with a peptide from a herpesvirus glycoprotein can induce a protective $\mathrm{CD} 8^{+} \mathrm{T}$ lymphocyte response $(42)$. The peptide of the nonstructural MCMV IE protein can be tested accordingly.

\section{ACKNOWLEDGMENTS}

We thank Anke Lüske and Irene Huber for technical assistance and Sabine Grau for preparation of the manuscript. J. P. Abastado and M. Cochet (Institute Pasteur, Paris, France) kindly supplied the $L / D^{d}$ and $L / K^{d}$ cells.

This work was supported by Deutsche Forschungsgemeinschaft grant Ko 571/8 and grant PTB 8614 of the Bundesministerium für Forschung und Technologie. M. Del Val is the recipient of an Alexander von Humboldt postdoctoral fellowship.

\section{LITERATURE CITED}

1. Avrameas, S., and T. Ternynck. 1969. The cross-linking of proteins with glutaraldehyde and its use for the preparation of immunoadsorbents. Immunochemistry 6:53-66.

2. Bjorkman, P. J., M. A. Saper, B. Samraoui, W. S. Bennett, J. L. Strominger, and D. C. Wiley. 1987. The foreign antigen binding site and $\mathrm{T}$ cell recognition regions of class $\mathrm{I}$ histocompatibility antigens. Nature (London) 329:512-518.

3. Borysiewicz, L. K., S. Graham, J. K. Hickling, P. D. Mason, and J. G. P. Sissons. 1988. Human cytomegalovirus-specific cytotoxic T cells: their precursor frequency and stage specificity. Eur. J. Immunol. 18:269-275.

4. Briand, J. P., S. Muller, and M. H. V. Van Regenmortel. 1985. Synthetic peptides as antigens: pitfalls of conjugation methods. J. Immunol. Methods 78:59-69.

5. Cochet, M., W. M. Kast, A.-M. Kummer, C. Transy, C. J. M. Melief, and P. Kourilsky. 1986. Alternative splicing in the mouse $\mathrm{H}-2 \mathrm{~K}^{\mathrm{d}}$ gene is not necessary for the classical $\mathrm{K}^{\mathrm{d}}$ antigen function. Immunogenetics 24:267-274.

6. Dente, L., G. Cesareni, and R. Cortese. 1983. pEMBL: a new family of single stranded plasmids. Nucleic Acids Res. 11:16451655 .

7. Ebeling, A., G. M. Keil, E. Knust, and U. H. Koszinowski. 1983. Molecular cloning and physical mapping of murine cytomegalovirus DNA. J. Virol. 47:421-433.

8. Gammon, G., N. Shastri, J. Cogswell, S. Wilbur, S. SadeghNasseri, U. Krzych, A. Miller, and E. Sercarz. 1987. The choice of T-cell epitopes utilized on a protein antigen depends on multiple factors distant from, as well as at the determinant site. Immunol. Rev. 98:53-73.

9. Guillet, J.-G., M.-Z. Lai, T. J. Briner, J. A. Smith, and M. L. Gefter. 1986. Interaction of peptide antigens and class II major histocompatibility complex antigens. Nature (London) 324:260- 
262.

10. Jonjić, S., M. del Val, G. M. Keil, M. J. Reddehase, and U. H. Koszinowski. 1988. A nonstructural viral protein expressed by a recombinant vaccinia virus protects against lethal cytomegalovirus infection. J. Virol. 62:1653-1658.

11. Keil, G. M., A. Ebeling-Keil, and U. H. Koszinowski. 1984. Temporal regulation of murine cytomegalovirus transcription and mapping of viral RNA synthesized at immediate early times after infection. J. Virol. 50:784-795.

12. Keil, G. M., A. Ebeling-Keil, and U. H. Koszinowski. 1987. Immediate-early genes of murine cytomegalovirus: location, transcripts, and translation products. J. Virol. 61:526-533.

13. Keil, G. M., A. Ebeling-Keil, and U. H. Koszinowski. 1987. Sequence and structural organization of murine cytomegalovirus immediate-early gene 1 . J. Virol. 61:1901-1908.

14. Keil, G. M., M. R. Fibi, and U. H. Koszinowski. 1985. Characterization of the major immediate-early polypeptides encoded by murine cytomegalovirus. J. Virol. 54:422-428.

15. Koszinowski, U. H., G. M. Keil, H. Schwarz, J. Schickedanz, and M. J. Reddehase. 1987. A nonstructural polypeptide encoded by immediate-early transcription unit 1 of murine cytomegalovirus is recognized by cytolytic T lymphocytes. J. Exp. Med. 166: 289-294.

16. Koszinowski, U. H., G. M. Keil, H. Volkmer, M. R. Fibi, A. Ebeling-Keil, and K. Münch. 1986. The $89,000-M_{\mathrm{r}}$ murine cytomegalovirus immediate-early protein activates gene transcription. J. Virol. 58:59-66.

17. Koszinowski, U. H., M. J. Reddehase, G. M. Keil, and J. Schickedanz. 1987. Host immune response to cytomegalovirus: products of transfected viral immediate-early genes are recognized by cloned cytolytic T lymphocytes. J. Virol. 61:2054-2058.

18. Lai, M.-Z., D. T. Ross, J.-G. Guillet, T. J. Briner, M. L. Gefter, and J. A. Smith. 1987. T lymphocyte response to bacteriophage $\lambda$ repressor cI protein. Recognition of the same peptide presented by Ia molecules of different haplotypes. J. Immunol. 139: 3973-3980.

19. Lemke, H., G. J. Hämmerling, and U. Hämmerling. 1979. Fine specificity analysis with monoclonal antibodies of antigens controlled by the major histocompatibility complex and by the $\mathrm{Qa} / \mathrm{TL}$ region in mice. Immunol. Rev. 47:175-206.

20. Margalit, H., J. L. Spouge, J. L. Cornette, K. B. Cease, C. DeLisi, and J. A. Berzofsky. 1987. Prediction of immunodominant helper $\mathrm{T}$ cell antigenic sites from the primary sequence. $\mathrm{J}$. Immunol. 138:2213-2229.

21. Meyers, J. D. 1984. Cytomegalovirus infection following marrow transplantation: risk, treatment, and prevention. Birth Defects Orig. Artic. Ser. 20:101-117.

22. Meyers, J. D., N. Flournoy, and E. D. Thomas. 1980. Cytomegalovirus infection and specific cell-mediated immunity after marrow transplant. J. Infect. Dis. 142:816-824.

23. Moskovitz, L., G. T. Hensley, J. C. Chan, and K. Adams. 1985. Immediate causes of death in acquired immunodeficiency syndrome. Arch. Pathol. Lab. Med. 109:735-738.

24. Osborn, J. E. 1981. Cytomegalovirus: pathogenicity, immunology, and vaccine initiatives. J. Infect. Dis. 143:618-630.

25. Quinnan, G. V., N. Kirmani, A. H. Rook, J. Manischewitz, L. Jackson, G. Moreschi, G. W. Santos, R. Saral, and W. H. Burns. 1982. HLA-restricted T lymphocyte and non-T-lymphocyte cytotoxic responses correlate with recovery from cytomegalovirus infection in bone-marrow-transplant recipients. N. Engl. J. Med. 307:7-13.

26. Reddehase, M. J., H.-J. Bühring, and U. H. Koszinowski. 1986. Cloned long-term cytolytic T-lymphocyte line with specificity for an immediate-early membrane antigen of murine cytomegalovirus. J. Virol. 57:408-412.
27. Reddehase, M. J., G. M. Keil, and U. H. Koszinowski. 1984. The cytolytic T lymphocyte response to the murine cytomegalovirus. II. Detection of virus replication stage-specific antigens by separate populations of in vivo active cytolytic $\mathrm{T}$ lymphocyte precursors. Eur. J. Immunol. 14:56-61.

28. Reddehase, M. J., and U. H. Koszinowski. 1984. Significance of herpesvirus immediate early gene expression in cellular immunity to cytomegalovirus infection. Nature (London) 312:369371.

29. Reddehase, M. J., W. Mutter, K. Münch, H.-J. Bühring, and U. H. Koszinowski. 1987. CD8-positive T lymphocytes specific for murine cytomegalovirus immediate-early antigens mediate protective immunity. J. Virol. 61:3102-3108.

30. Reddehase, M. J., F. Weiland, K. Münch, S. Jonjić, A. Lüske, and U. H. Koszinowski. 1985. Interstitial murine cytomegalovirus pneumonia after irradiation: characterization of cells that limit viral replication during established infection of the lungs. J. Virol. 55:264-273.

31. Reddehase, M. J., R. Zawatzky, F. Weiland, H.-J. Bühring, W. Mutter, and U. H. Koszinowski. 1987. Stable expression of clonal specificity in murine cytomegalovirus-specific large granular lymphoblast lines propagated long-term in recombinant interleukin-2. Immunobiology 174:420-431.

32. Rothbard, J. B., R. I. Lechler, K. Howland, V. Bal, D. D. Eckels, R. Sekaly, E. O. Long, W. R. Taylor, and J. R. Lamb. 1988. Structural model of HLA-DR1 restricted T cell antigen recognition. Cell 52:515-523.

33. Rothbard, J. B., and W. R. Taylor. 1988. A sequence pattern common to T cell epitopes. EMBO J. 7:93-100.

34. Schwartz, R. H. 1985. T-lymphocyte recognition of antigen in association with gene products of the major histocompatibility complex. Annu. Rev. Immunol. 3:237-261.

35. Shastri, N., A. Oki, A. Miller, and E. E. Sercarz. 1985. Distinct recognition phenotypes exist for $\mathrm{T}$ cell clones specific for small peptide regions of proteins. J. Exp. Med. 162:332-345.

36. Shimonkevitz, R., J. Kappler, P. Marrack, and H. Grey. 1983. Antigen recognition by $\mathrm{H}-2$-restricted T cells. I. Cell-free antigen processing. J. Exp. Med. 158:303-316.

37. Tanaka, Y., M. J. Tevethia, D. Kalderon, A. E. Smith, and S. S. Tevethia. 1988. Clustering of antigenic sites recognized by cytotoxic $\mathrm{T}$ lymphocyte clones in the amino terminal half of SV40 T antigen. Virology 162:427-436.

38. Taylor, P. M., J. Davey, K. Howland, J. B. Rothbard, and B. A. Askonas. 1987. Class I MHC molecules rather than other mouse genes dictate influenza epitope recognition by cytotoxic $\mathrm{T}$ cells. Immunogenetics 26:267-272.

39. Townsend, A. R. M., F. M. Gotch, and J. Davey. 1985. Cytotoxic $\mathrm{T}$ cells recognize fragments of the influenza nucleoprotein. Cell 42:457-467.

40. Townsend, A. R. M., J. Rothbard, F. M. Gotch, G. Bahadur, D. Wraith, and A. J. McMichael. 1986. The epitopes of influenza nucleoprotein recognized by cytotoxic $\mathrm{T}$ lymphocytes can be defined with short synthetic peptides. Cell 44:959-968.

41. Volkmer, H., C. Bertholet, S. Jonjić, R. Wittek, and U. H. Koszinowski. 1987. Cytolytic T lymphocyte recognition of the murine cytomegalovirus nonstructural immediate-early protein pp89 expressed by recombinant vaccinia virus. J. Exp. Med. 166:668-677.

42. Watari, E., B. Dietzschold, G. Szokan, and E. Heber-Katz. 1987. A synthetic peptide induces long-term protection from lethal infection with herpes simplex virus 2. J. Exp. Med. 165:459470.

43. Whitton, J. L., J. R. Gebhard, H. Lewicki, A. Tishon, and M. B. A. Oldstone. 1988. Molecular definition of a major cytotoxic T-lymphocyte epitope in the glycoprotein of lymphocytic choriomeningitis virus. J. Virol. 62:687-695. 